\title{
Acute circulatory effects of dopamine in patients with pulmonary hypertension ${ }^{\mathrm{j}, 2}$
}

\author{
Earl L. Holloway, ${ }^{3}$ Ralph A. Polumbo, ${ }^{4}$ and Donald C. Harrison \\ From The Cardiology Division, Stanford University School of Medicine, Stanford, California, U.S.A.
}

Twenty-one patients, II with normal pulmonary artery pressures and 10 with pulmonary hypertension, had haemodynamic measurements performed before and during dopamine infusion while undergoing cardiac catheterization, in order to evaluate the circulatory effects of dopamine in pulmonary hypertension. In both groups on average, heart rate, pulmonary artery mean pressure, aortic mean pressure, and cardiac index increased significantly, while systemic vascular resistance fell significantly during dopamine administration. In neither group did the average pulmonary vascular resistance or right ventricular end-diastolic pressure change significantly. We conclude that dopamine is a safe and potentially useful drug for the treatment of reduced cardiac output, even in patients with pulmonary hypertension.

Dopamine is a naturally occurring catecholamine which is the direct biochemical precursor in the synthesis of norepinephrine (Blaschko, I957). Its use has been advocated for the treatment of shock (Goldberg, 1972; Harrison et al., 1969; Loeb et al., 197I), and in the low output syndrome associated with cardiac surgery (MacCannell et al., I966). These, and other studies summarized by Rosenblum and Frieden (1972) and Goldberg (1972) have demonstrated that dopamine is a potent stimulator of myocardial contractile state which appears to cause a smaller increase in heart rate for a given increase in contractility than other adrenergic agents. In the systemic circulation, dopamine acts primarily as an $\alpha$-adrenergic stimulator, but this is countered by direct coeliac, mesenteric, and renal artery dilatation resulting in increased renal blood flow and urine output (Talley et al., 1969).

Dopamine's effect on the pulmonary circulation has been less extensively studied. Waller (196I) demonstrated vasoconstriction in a perfused pulmonary vascular bed. Studies carried out in our laboratory in animal models (Harrison et al., 1969)

\footnotetext{
Received 16 October 1974.

${ }^{1}$ This work was supported in part by NIH Grant and Program Project Grant.

2 Presented in part at the Annual Meeting of the American Heart Association, Dallas, Texas, November 1972.

${ }^{3}$ Fellow, Bay Area Heart Research Committee.

Present address: 3326 Webster Street, Oakland, California 94609, U.S.A.

${ }^{4}$ Present address: Cardiology Associates of Canton, Inc., 214 Dartmouth Avenue SW, Canton, Ohio 447Io, U.S.A.
}

indicated that dopamine caused a pressor reponse in the pulmonary circulation which suggested that in patients with pulmonary hypertension, dopamine might prove detrimental. This might occur if dopamine administration resulted in an increase in pulmonary arteriolar constriction when pulmonary pressures were already increased by direct vascular changes, hypoxia, or arterial hypercarbia. Thus, dopamine administration in patients with an already raised pulmonary resistance might result in acute right heart failure and even more severe pulmonary hypertension.

In order to test this hypothesis, acute studies were carried out in the cardiac catheterization laboratory on a group of patients with normal pulmonary arterial pressures and a group of patients with raised pulmonary artery pressures. Dopamine was administered to both groups and their circulatory responses compared.

\section{Subjects and methods}

Twenty-one patients undergoing routine diagnostic cardiac catheterization were studied, II with normal resting pulmonary artery pressure (pulmonary artery mean pressure $\leq \mathbf{2 0} \mathbf{m m H g}(2.7 \mathrm{kPa})$ ) and ro with pulmonary hypertension (pulmonary artery pressure $\geq 30$ $\mathrm{mmHg}(4.0 \mathrm{kPa})$ ). All had disease affecting left ventricular function, either coronary artery disease or cardiomyopathy, and none had primary valvular heart disease or primary pulmonary hypertension. Informed consent was obtained for the investigation before the diagnostic study. 
At the end of the diagnostic catheterization, control haemodynamic measurements were obtained, including mean right atrial, mean pulmonary artery, mean pulmonary capillary wedge, and mean aortic and left ventricular end-diastolic pressures. In addition, cardiac outputs were determined using standard Fick or indicator dilution techniques. A comparison of indicator dilution techniques for cardiac output using a computer with the Fick method was recently made in our laboratory (Stenson, Crouse, and Harrison, 1972) and showed excellent agreement. From these data cardiac index, pulmonary vascular resistance (pulmonary arterial mean pulmonary capillary wedge mean $(\mathrm{mmHg}) /$ cardiac output $(\mathrm{I} / \mathrm{min})$ ), and systemic vascular resistance (aortic mean - right atrial mean $(\mathrm{mmHg}) / \mathrm{cardiac}$ output $(\mathrm{I} / \mathrm{min}))$ were calculated.

Following these control measurements, an infusion of dopamine $(100 \mu \mathrm{g} / \mathrm{ml})$ was begun at a rate of $2 \mu \mathrm{g} \mathrm{kg} \mathrm{kg}^{-1}$ $\min ^{-1}$. Every 5 minutes this dose rate was increased by $2 \mu \mathrm{g} \mathrm{kg}^{-1} \mathrm{~min}^{-1}$ until the patient increased his mean aortic pressure by about $15 \mathrm{mmHg}(2.0 \mathrm{kPa})$, or until his heart rate increased by 30 beats $/ \mathrm{min}$. When the patient had achieved the appropriate increase in mean aortic pressure, the infusion rate was kept constant for an additional 5 minutes, then the haemodynamic measurements were repeated. The dopamine infusion rate required to obtain the desired end-point ranged from 2 to $16 \mu \mathrm{g} \mathrm{kg}^{-1} \mathrm{~min}^{-1}$. All statistical analyses were performed using Student's $t$ test for paired samples, or for unpaired samples with equal variance, and a $P$ value of less than 0.05 was taken as indicative of statistical significance.

\section{Results}

The haemodynamic responses to dopamine infusion of II patients with normal pulmonary artery mean pressures averaging $13.7 \pm 3.4 \mathrm{mmHg}$ ( $1.8 \pm 0.4$ $\mathrm{kPa}$ ) are summarized in Table $\mathrm{I}$, and those of 10 patients with pulmonary hypertension and pulmonary artery mean pressures averaging $38.2 \pm 7.4$ $\mathrm{mmHg}(5 . \mathrm{I} \pm 0.9 \mathrm{kPa})$ are listed in Table 2. Both groups showed significant and comparable increases of 12.1 and $13.0 \mathrm{mmHg}$ (1.6 and $1.7 \mathrm{kPa}$ ) in mean aortic pressure, the end-point for control of the dopamine infusion rate. Heart rate increased significantly by a mean of 13 beats/min in the control group, and a mean of 20 beats/min in the group with pulmonary hypertension. Dopamine infusion significantly increased pulmonary artery mean pressure by $4.1 \mathrm{mmHg}(0.5 \mathrm{kPa})$ in the group with normal pulmonary artery pressures, and 10.3 $\mathrm{mmHg}(1.3 \mathrm{kPa})$ in the pulmonary hypertension group. Cardiac index was increased by 1.7 and $1.01 \mathrm{~min}^{-1} \mathrm{~m}^{-2}$, respectively. Calculated systemic vascular resistance fell by 5.4 resistance units in the control group, and 6.6 resistance units in the group with raised pulmonary pressure. The mean calculated pulmonary vascular resistance showed no significant change in either group, despite the rise in
TABLE I Haemodynamics in II patients with normal pulmonary artery pressure before and during dopamine infusion (mean $\pm I S D$ )

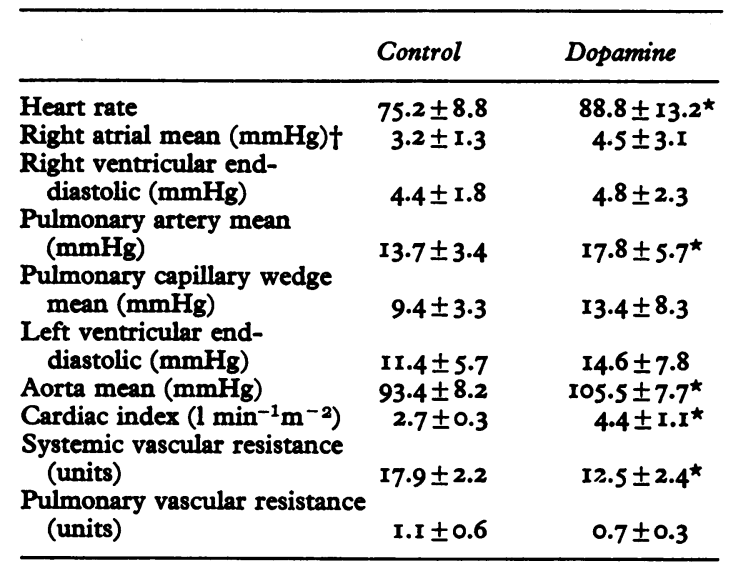

$\star \mathbf{P}<0.05$

† To convert pressures (mmHg) into Pascal units (kPa) multiply by 0.133 .

TABLE 2 Haemodynamics in 10 patients with raised pulmonary artery pressure before and during dopamine infusion (mean $\pm I S D$ )

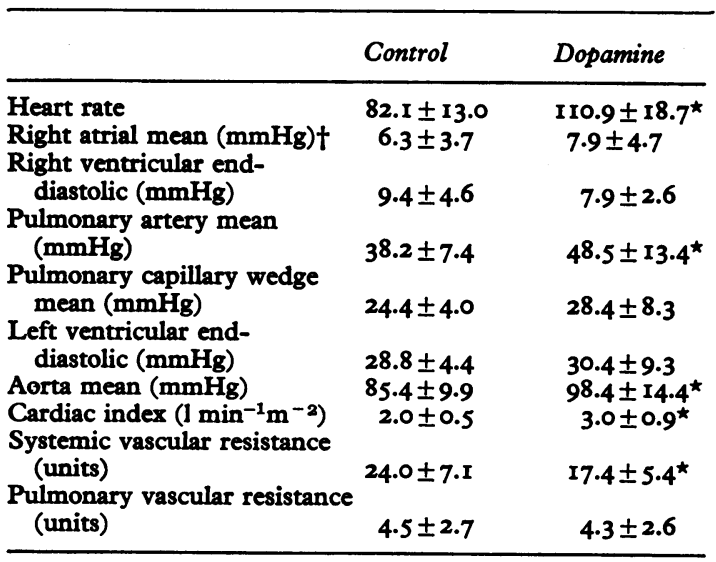

$\star \mathbf{P}<0.05$

† To convert pressures ( $\mathrm{mmHg}$ ) into Pascal units (kPa) multiply by 0.133 . 
mean pulmonary artery pressure though four individual patients in the hypertensive group did show a rise (Fig.). Finally, neither group had a significant change in right or left ventricular end-diastolic pressure.

\section{Discussion}

Dopamine's circulatory effect in patients with high pulmonary artery pressures has not been systematically studied previously. We, therefore, selected a group of patients without primary valvular heart disease who had moderate pulmonary hypertension secondary to chronic left ventricular dysfunction, a group analogous to those patients in whom dopamine might be administered clinically. In addition, a group of patients with similar diseases, coronary artery disease, or cardiomyopathy, who did not have pulmonary hypertension, was studied. The indication that the group with pulmonary hypertension represents patients with advanced cardiac disease is supported by the observation that this group had a significantly higher resting heart rate, left ventricular end-diastolic pressure, and systemic vascular resistance, and a lower cardiac index as compared to the group with normal pulmonary pressures.

Dopamine administration, in the moderate dose range used, again demonstrated its effectiveness in increasing cardiac index and reducing calculated systemic vascular resistance, presumably through its vasodilatation of the splanchnic vascular bed (Rosenblum, Tai, and Lawson, 1972). This increase in cardiac index occurred in both patient groups, though the group with pulmonary hypertension had a greater accompanying increase in heart rate, and therefore in myocardial oxygen demands.

In both groups, dopamine infusion resulted in significant increases in pulmonary artery pressure. However, in neither group did the mean calculated pulmonary vascular resistance increase though it did in 4 patients with pulmonary hypertension (Fig.). Therefore, the rise in pulmonary artery pressure after dopamine administration generally was not the result of an increase in pulmonary vascular constriction, but rather was secondary to increased right heart output. This was true both for patients with normal pulmonary artery pressure and for patients with raised pulmonary artery pressure. Significant decreases in systemic vascular resistance occurred in both groups of patients, and, though slight decreases in pulmonary vascular resistance occurred in individual subjects, the mean change was not statistically significant in either group. There was no significant increase in right ventricular end-diastolic pressure suggestive of right heart
NORMAL PULMONARY ARTERY PRESSURE $(\mathrm{N}=10)$

ELEVATED PULMONARY

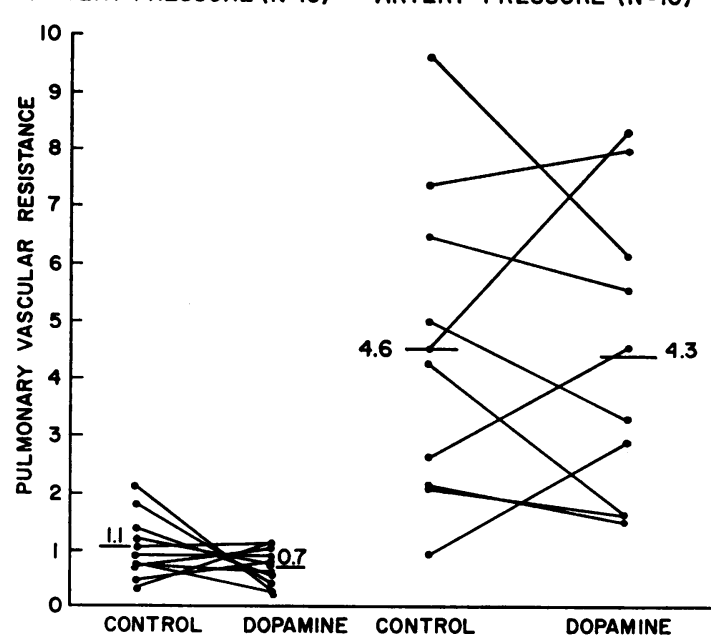

FIG. Changes in pulmonary vascular resistance with dopamine administration in 10 patients with normal pulmonary artery pressures and 10 patients with pulmonary hypertension.

failure, even with the increase in pulmonary pressure. Since dopamine stimulates an increase in the contractile state of the ventricle, this result might be expected.

Previous experimental work (Waller, 196I) has suggested that in pulmonary hypertension in low output syndromes in dogs, dopamine may further increase pulmonary vascular resistance. Our studies in man show that in mild to moderate pulmonary hypertension the administration of dopamine does not usually produce pulmonary vasoconstriction. Though the pulmonary artery pressure rises this is generally caused by the increase in blood flow and not by an increase in pulmonary vascular resistance. While it is dangerous to extrapolate these results to patients with severe hypoxia, low cardiac outputs, and severe pulmonary hypertension, it appears that dopamine improves ventricular function and, therefore, should improve the overall circulatory status even in these critically ill patients.

Finally, our studies clearly show that dopamine is an excellent agent for improving the circulatory state of patients with decreased ventricular function. Its administration in moderate doses augmented cardiac output and diminished systemic vascular resistance.

\section{References}

Blaschko, H. (1957). Formation of catecholamines in the animal body. British Medical Bulletin, 13, 162. 
Goldberg, L. I. (1972). Cardiovascular and renal actions of dopamine: potential clinical applications. Pharmacological Reviews, 24, $\mathrm{I}$.

Harrison, D. C., Pirages, S., Robison, S. C., and Wintroub, B. U. (1969). The pulmonary and systemic circulatory response to dopamine infusion. British Fournal of Pharmacology, 37, 618 .

Loeb, H. S., Winslow, E. B. J., Rahimtoola, S. H., Rosen, K. M., and Gunnar, R. M. (I97I). Acute hemodynamic effects of dopamine in patients with shock. Circulation, 44, 163.

MacCannell, K. L., McNay, J. L., Meyer, M. B., and Goldberg, L. I. (1966). Dopamine in the treatment of hypotension and shock. New England fournal of Medicine, 275, I 389.

Rosenblum, R., and Frieden, J. (1972). Intravenous dopamine in the treatment of myocardial dysfunction after open-heart surgery. American Heart fournal, 83, 743.
Rosenblum, R., Tai, A. R., and Lawson, D. (1972). Dopamine in man: cardiorenal hemodynamics in normotensive patients with heart disease. fournal of Pharmacology and Experimental Therapeutics, 183, 256.

Stenson, R., Crouse, L., and Harrison, D. C. (1972). Computer measurement of cardiac output by dye dilution: comparison of computer, Fick, and Dow techniques. Cardiovascular Research, 6, 449.

Talley, R. C., Goldberg, L. I., Johnson, C. E., and McNay, J. L. (1969). A hemodynamic comparison of dopamine and isoproterenol in patients in shock. Circulation, 39, 36r.

Waller, B. A. (196I). The effect of dopamine on the isolated perfused lung lobes of the dog. British fournal of Pharmacology, 16, 195 .

Requests for reprints to Dr. Donald C. Harrison, Cardiology Division, Stanford University School of Medicine, Stanford, California 94305, U.S.A. 